\title{
Tyrosine Kinase Inhibitors and Reduced-Dose Chemotherapy for Adult Philadelphia Chromosome- Positive Acute Lymphoblastic Leukemia
}

chunping wu

Fujian Medical University Union Hospital https://orcid.org/0000-0002-5386-3278

mengting zeng

Fujian Medical University Union Hospital

yuanzhong chen ( $\sim 26680315 @ q q . c o m c)$

Fujian Medical University Union Hospital https://orcid.org/0000-0002-0614-3219

yong wu

Fujian Medical University Union Hospital

\section{Research Article}

Keywords: Philadelphia chromosome-positive acute lymphoblastic leukemia, Tyrosine kinase inhibitors, Reduced-dose chemotherapy, Pharmacoeconomics, Transplantation Subject classification codes: 320.2430

Posted Date: June 4th, 2021

DOI: https://doi.org/10.21203/rs.3.rs-585347/v1

License: (1) This work is licensed under a Creative Commons Attribution 4.0 International License. Read Full License 


\section{Abstract}

Purpose: To compare the outcomes of tyrosine kinase inhibitors in combination with reduced-dose chemotherapy with those of standard induction chemotherapy and to compare the outcomes between TKls with chemotherapy regimen and transplantation in adults with Philadelphia chromosome-positive acute lymphoblastic leukemia

Methods: We retrospectively reviewed all patients treated with tyrosine kinase inhibitors in combination with chemotherapy. These patients were divided into the TKIs with reduced-dose chemotherapy group (62 patients) and the TKIs with standard chemotherapy group (143 patients). In further treatment, patients were divided into the transplant group (55 patients) and the non-transplant group (143 patients).

Results: The complete remission rate $(88.7 \%$ vs $83.9 \%, P=0.372)$ and early mortality rate $(3.2 \%$ vs $3.5 \%$, $\mathrm{P}=0.922)$ were similar between the TKls with reduced-dose chemotherapy group and the TKIs with standard chemotherapy group. The proportions of lung infection $(P=0.047)$ and bloodstream infection $(P=0.024)$ and the proportion of patients with $>21$ days of hospitalization $(P<0.001)$, on $>4$ types of antibiotics $(P=0.003)$, and on restrictive tigecycline and/or polymyxin $(P=0.031)$ were higher in the standard chemotherapy group than in the TKIs with reduced-dose chemotherapy group. For cost analysis, the total costs and antimicrobial costs were higher in the standard chemotherapy group than in the TKIs with reduced-dose chemotherapy group. The 3-year overall survival rates and 3-year disease-free survival rates were significantly better in the transplant group than in the non-transplant group.

Conclusion: An induction regimen combining TKls with reduced-dose chemotherapy and transplantation in first CR remains a good option for patients with Ph+ALL.

\section{Introduction}

Philadelphia $(\mathrm{Ph}+)$ chromosome-positive acute lymphoblastic leukemia $(\mathrm{Ph}+\mathrm{ALL})$ is a subtype of $\mathrm{ALL}$ with a poor prognosis, and its incidence increases with age, accounting for $3-5 \%$ of childhood ALL, 20$30 \%$ of adult ALL, and even greater than $50 \%$ of elderly ALL (> 50 years) (Ottmann, 2013). Before the advent of tyrosine kinase inhibitors (TKIs), the standard ALL chemotherapy regimens for Ph + ALL resulted in a complete remission (CR) rate of at least $10 \%$ lower than $\mathrm{Ph}-\mathrm{ALL}$, which has a median survival time of approximately 8 months. The use of TKIs has increased the remission rate to over $90 \%$ for patients with $\mathrm{Ph}+\mathrm{ALL}$ and has reduced the incidence of adverse events in older patients, allowing more opportunities for allogeneic hematopoietic stem cell transplantation (allo-HSCT) and significantly prolonging remission and survival in patients who were not able to undergo transplantation (Fielding \& Zakout, 2013). Allo-HSCT is considered to be the only treatment option to achieve long-term survival after CR; however, its 5-year overall survival (OS) rate is only approximately 50\% (Hatta et al., 2018; Liu, Yang, \& Feng, 2015). The survival of patients with $\mathrm{Ph}+\mathrm{ALL}$ has improved greatly, with the 5-year OS rate increasing to $40-70 \%$ and the efficacy of non-transplant treatment gradually approaching that of alloHSCT with the use of TKIs (Salami et al., 2013). Although the clinical efficacy of TKIs combined with 
chemotherapy has been confirmed, not all patients can tolerate chemotherapy, and high-dose chemotherapy often results in severe myelosuppression or complications such as infection and bleeding, leading to early death. Moreover, for patients who cannot tolerate standard chemotherapy, TKIs with lowdose chemotherapy have shown good results. In the GRAAPH-2005 clinical trial conducted by Chalandon et al. (Y Chalandon et al., 2015), 268 patients were randomized into two groups to receive imatinib combined with low-dose chemotherapy (vincristine + dexamethasone, VP regimen) and imatinib combined with hyper-CVAD chemotherapy during the induction phase, respectively. Subsequently, after achieving first CR (CR1), they underwent allo-HSCT or auto-HSCT, with CR rates of $98 \%$ and $91 \%(\mathrm{P}=$ 0.006), complete molecular response (CMR) rates of $29 \%$ and $23 \%$ after two courses of therapy, and 5year OS rates of $48 \%$ and $43 \%$, respectively, with $60 \%$ of patients in both groups undergoing allo-HSCT at CR1. The study showed that the CR rate was not lower or even higher with TKIs combined with low-dose chemotherapy regimens, probably due to the reduced early mortality with low-dose chemotherapy (Abou Dalle, Jabbour, Short, \& Ravandi, 2019). Researchers in the European Working Group on Adult ALL (EWALL) have conducted clinical trials for older patients as well. In 56 patients (median age, 65 years) who were treated with nilotinib combined with low-dose chemotherapy during the induction phase, the outcome was observed, with a CR rate of $87 \%$ and a 2 -year OS rate of $73 \%$ based on no allo-HSCT (Shen \& Zhu, 2020). This indicates that TKIs combined with low-dose chemotherapy are clinically feasible for elderly patients unable to tolerate standard chemotherapy and transplantation. To explore more appropriate induction chemotherapy regimens for patients with adult $\mathrm{Ph}+\mathrm{ALL}$, our study retrospectively analyzed the clinical data of 205 patients newly diagnosed with adult Ph + ALL in our hospital between January 2010 and December 2020. This study compared the efficacy and pharmacoeconomics of lowdose chemotherapy combined with TKIs and standard chemotherapy combined with TKls during the induction chemotherapy period and analyzed the factors affecting their prognosis to determine rational treatment strategies and provide new ideas for prognostic stratification and individualized treatment of with $\mathrm{Ph}+\mathrm{ALL}$ patients.

\section{Methods}

\section{Study design}

Based on the World Health Organization (WHO) classification, 205 patients aged 14-73 years with newly diagnosed Ph + ALL were evaluated. The patients were treated at Fujian Union Hospital of Hematology, China, between January 2010 and December 2020. Patients with known severe cardiac, pulmonary, hepatic, or renal dysfunction; non-primary patients; patients who abandoned treatment after diagnosis; and pregnant patients were excluded from this study. This study was approved by the ethics review board of the Fujian Medical University Union Hospital. Depending on induction chemotherapy, patients were divided into the TKIs with reduced-dose chemotherapy group (VP, VIP, VDP) and the TKIs with standard chemotherapy group (VICLP, VDCLP, VICP, VDCP, hyper-CVAD). In further treatment, patients were divided into the transplant group and non-transplant group.

\section{Diagnosis}


ALL was diagnosed according to the 2016 WHO criteria (Bene et al., 1998; Bene et al., 1995; Haferlach, Bacher, Kern, Schnittger, \& Haferlach, 2007), using karyotyping, fluorescence in situ hybridization, and real-time quantitative polymerase chain reaction-based detection of BCR-ABL1 fusion transcripts. CR was defined as absence of primitive cells in peripheral blood, absence of extramedullary leukemia, leukemia cells $<5 \%$ in the bone marrow, and neutrophil count $>1.0 \times 10^{\wedge} 9 / \mathrm{L}$ and platelet count $>100 \times 10^{\wedge} 9 / \mathrm{L}$. Early death was defined as death during the induction treatment. Relapse was defined as $>5 \%$ of leukemia cells in peripheral blood or bone marrow in patients who have achieved CR or experienced extramedullary disease. OS is defined as the time from the date of diagnosis to the date of death or final follow-up date. Disease-free survival (DFS) was measured from the date of complete remission to the date of disease relapse, death, or final follow-up date.

\section{Chemotherapy}

Chemotherapy regimen was based on the Expert Consensus on the Diagnosis and Treatment of Adult ALL guidelines in China ("[Chinese guidelines for diagnosis and treatment of acute lymphoblastic leukemia(2016)]," 2016). Chemotherapy medications used in induction therapy included vincristine or vincristine, anthracyclines/anthraquinones, and glucocorticoid-based regimens (VDP) combined with cyclophosphamide (CTX) and L-asparaginase (L-ASP) or pegaspargase comprising VDCLP regimen or hyper-CVAD regimen, a regimen comprising cyclophosphamide, vincristine, doxorubicin, and dexamethasone. After establishing the diagnosis of Ph/BCR-ABL-positive ALL, patients received the $\mathrm{Ph}+$ ALL treatment without L-ASP.

\section{Tyrosine kinase inhibitors (TKIs)}

All patients were treated with a combination of TKIs in induction chemotherapy: imatinib (400-600 $\mathrm{mg} / \mathrm{d}$ ), dasatinib (100-140 mg/d), and nilotinib (400-800 mg/d) in 156, 47, and 2 patients, respectively. These treatment regimens were discontinued when neutrophil counts were $<0.2 \times 10^{\wedge} 9 / \mathrm{L}$ and resumed when neutrophil counts were $>0.2 \times 10^{\wedge} 9 / \mathrm{L}$ during induction, consolidation, and maintenance treatment.

\section{Transplantation}

Of the 55 patients who underwent allo-HSCT, 18 had cord blood HSCT, 7 had cord blood combined with related allo-HSCT, 28 had related allo-HSCT, and 2 had unrelated allo-HSCT. The remaining patients were unable to undergo HSCT due to insufficient matching HSCT donors or personal reasons.

\section{Statistical analyses}

All statistical analyses were performed using the Statistical Package for the Social Sciences version 26.0 software. Normally and non-normally distributed data are expressed as mean \pm standard deviation and median (range), respectively. The survival curves were estimated using the Kaplan-Meier method, and the survival curves of each group were compared using the log-rank test. Factors associated with DFS and OS were investigated using a Cox proportional risk model. Hazard ratios were obtained with the 95\% confidence interval. $\mathrm{P}<0.05$ was considered statistically significant for every test. 


\section{Results}

\section{Patient characteristics}

In this study, 234 patients were newly diagnosed with $\mathrm{Ph}+\mathrm{ALL}$, and 29 were excluded because they received chemotherapy without TKls. Therefore, 205 patients with $\mathrm{Ph}+\mathrm{ALL}$ were included from January 2010 to December 2020. Patient characteristics are shown in Table 1.

\section{Response to TKls with reduced-dose chemotherapy versus TKls with standard chemotherapy}

\section{Complete remission rate and early mortality}

In the TKIs with reduced-dose chemotherapy group, in induction chemotherapy, 55 of the 62 (88.7\%) patients achieved CR, whereas 7 of the $62(11.3 \%)$ patients did not achieve CR. Moreover, in the TKIs with standard chemotherapy group, in induction chemotherapy, 120 of the 143 (83.9\%) patients achieved CR, whereas 23 of the $143(16.1 \%)$ patients did not achieve CR. The CR rate in the two groups had no statistically significant difference $(P=0.372)$. Furthermore, early deaths were observed in 2 of the 62 (3.2\%) patients in the TKls with reduced-dose chemotherapy group and 5 in the 143 (3.5\%) patients in the TKIs with standard chemotherapy group. The difference between the two groups was not statistically significant $(P=0.922)$.

\section{Complications}

According to the statistical results, the TKls with reduced-dose chemotherapy group reduced the incidence of pulmonary infection and bloodstream infection ( $P=0.047$ and 0.024 , respectively) (Table 2).

\section{Number of hospital days and inpatient costs in induction chemotherapy}

The mean numbers of hospital days in the TKls with reduced-dose chemotherapy group and the TKIs with standard chemotherapy group were $23 \pm 7$ days and $27 \pm 8$ days, respectively. According to the data, $52.4 \%$ (33/62 patients) of patients in the TKIs with reduced-dose chemotherapy group were hospitalized for $>21$ days, whereas $80.4 \%$ (115/143 cases) of patients in the TKIs with standard chemotherapy group were hospitalized for $>21$ days. The result between the two groups was statistically significant $(P<0.001)$. The total costs in the TKIs with reduced-dose chemotherapy group and the TKIs with standard chemotherapy group were $(¥) 51,185 \pm 3586$ and $73,309 \pm 3610$, respectively, with a statistically significant difference $(P=0.026)$ (Table 3).

\section{Antibiotic use in induction chemotherapy}


In the present study, the type and intensity of antibiotics used to control infections during the patients' hospitalization were recorded. The results showed that $22.6 \%$ (14/62 patients) and 44.8\% (64/143 patients) of patients in the TKIs with reduced-dose chemotherapy group and the TKIs with standard chemotherapy group received $>4$ antibiotics to control infection, respectively, a statistically significant difference $(P=0.003)$. Regarding antibiotic intensity, 61.3\% (38/62 patients) and 74.8\% (107/143 patients) of patients in the TKIs with reduced-dose chemotherapy group and the TKIs with standard chemotherapy group used carbapenems, respectively, with no statistically significant difference $(P=0.057)$. The rates of use of the restricted class of anti-positive drugs (tigecycline, vancomycin, and linezolid) were $50.0 \%$ (31/62 patients) and $61.5 \%$ (88/143 patients) in the TKIs with reduced-dose chemotherapy group and the TKls with standard chemotherapy group, respectively, with no statistically significant difference $(P=0.247)$. The rates of use of restricted tigecycline and/or polymyxin were $1.6 \%$ (1/62 patients) and $10.5 \%$ (15/143 patients) in the TKIs with reduced-dose chemotherapy group and the TKIs with standard chemotherapy group, respectively, with a statistically significant difference $(P=0.031)$. The rates of antifungal use were $54.8 \%$ (34/62 patients) and $62.9 \%$ (90/143 patients) in the TKIs with reduced-dose chemotherapy group and the TKIs with standard chemotherapy group, respectively, with no statistically significant difference $(P=0.309)$ (Table 4).

\section{Survival outcomes in the transplant group versus the non-transplant group}

The median OS rates in the transplant group and the non-transplant group were 31 (range, 4-106) and 19 (range, 1-102) months, respectively, and the 3 -year OS rates in the two groups were $53.7 \%$ and $37.5 \%$, respectively ( $P=0.022)$, a statistically significant difference. The median DFS rates were 26 (range, 1105) and 12 (range, 1-83) months in the transplant and non-transplant groups, respectively, and the 3year DFS rates were $49.7 \%$ and $33.4 \%$ in the transplant and non-transplant groups, respectively $(P=0.007)$, a statistically significant difference (Figure 1).

\section{Prognostic factors}

A multivariate analysis of the prognostic factors of DFS and OS of the enrolled patients with Ph+ALL using Cox regression (Table 5) showed that age, white blood cell (WBC) count, and CR in induction chemotherapy had a significant effect on OS and DFS.

\section{Discussion}

$\mathrm{Ph}+\mathrm{ALL}$ is the most common group of cytogenetic abnormalities in adult ALL and is a subtype with a poor prognosis. In the pre-TKI era, conventional chemotherapy regimens were used to treat adults with $\mathrm{Ph}$ + ALL with a long-term survival rate of only $10 \%$ (Leoni \& Biondi, 2015), characterized by low CR, short duration of remission, low long-term survival rates, and high relapse rates. Using TKIs, the treatment pattern, efficacy, and prognosis of patients with adult $\mathrm{Ph}+\mathrm{ALL}$ have changed dramatically, with CR rates of over $90 \%$ and OS rates of $40-60 \%$, significantly improving the disease outcome and prognosis (Fielding \& Zakout, 2013). 
In this study, univariate and multivariate analyses of disease data at presentation in the 205 patients with $\mathrm{Ph}+\mathrm{ALL}$ showed that WBC count, age, and CR in induction chemotherapy were independent prognostic factors affecting $O S$ and DFS, a result consistent with that reported by Fielding et al. (Fielding et al., 2009 ) in 2009, suggesting higher WBC count and older age were associated with worse prognosis.

One of the reasons for the poor prognosis of patients with $\mathrm{Ph}+\mathrm{ALL}$ is the low rate of induction remission. In the era of TKIs, TKIs combined with chemotherapy has become the first-line induction chemotherapy regimen for patients newly diagnosed with $\mathrm{Ph}+\mathrm{ALL}$, improving the $\mathrm{CR}$ rate and OS and DFS rates while reducing treatment-related mortality (Fielding, 2010; Fielding et al., 2014). Additionally, this has led to the consideration of chemotherapy regimens and whether high-intensity chemotherapy is still needed for induction remission with potent targeted agents, especially in elderly patients, where complications such as severe myelosuppression or infection caused by high-intensity chemotherapy often cause interruption of chemotherapy or early death in some patients. Hence, several international clinical studies of TKIs with reduced-dose chemotherapy have been conducted. The EWALL studied the clinical efficacy of dasatinib combined with low-dose chemotherapy, enrolling 71 elderly patients with a median age of 69 (55-83) years and with CR rate, CMR rate, and MMR rates of $96 \%, 24 \%$, and $65 \%$, respectively. Moreover, only $10 \%$ of patients underwent allo-HSCT, with 5-year RFS and OS rates of $28 \%$ and $36 \%$, respectively (Rousselot et al., 2016). In the European study by Foà et al., dasatinib (70 mg twice daily) was used combined with prednisone $\left(10-60 \mathrm{mg} / \mathrm{m}^{2}\right)$ for 84 days. In this trial, 53 patients were enrolled, with a median age of 54 (24-76) years and CR, MMR, CMR, and OR rates of $93 \%, 52 \%, 15 \%$, and $69 \%$ at 20 months, respectively (Foà et al., 2011). Similar results were obtained in another clinical trial with a CR rate of $96 \%$ and a 3-year OS rate of $59.1 \%$ in 49 patients (Chiaretti et al., 2016). In addition to dasatinib, the clinical efficacy of ponatinib with glucocorticoids has been studied. In the GIMEMA LAL 1811 clinical trial, 42 patients (median age, 68 years) had CR, CMR, and 1 -year OS rates of $95 \%, 46 \%$, and nearly $87 \%$, respectively, after using ponatinib with glucocorticoids (Martinelli et al., 2017). The above study showed that reducing the intensity of chemotherapy did not reduce the remission rate or survival time of patients. Rather, the reduced intensity of chemotherapy allowed patients to achieve high CR while significantly reducing the toxic side effects of chemotherapy and reducing the associated mortality. In this study, patients were divided into the TKls with reduced-dose chemotherapy group (62 patients) and the TKIs with standard chemotherapy group (143 patients) based on the induction chemotherapy, with CR rates $(88.7 \%$ vs $83.9 \%$, $P=0.372)$ and early mortality $(3.2 \%$ vs $3.5 \%, P=0.922)$ in both groups not statistically significant. Thus, it was observed that the induction chemotherapy of TKIs combined with low-dose chemotherapy had a high CR and an early mortality rate of $<5 \%$. However, the present study was a retrospective analysis, and the induction regimen was not standardized. Therefore, strategies on how to optimize post-remission outcomes for patients who cannot tolerate strong chemotherapy need to be determined in the future.

$\mathrm{Ph}+\mathrm{ALL}$ is a hematological malignancy and a chronic disease that requires repeated hospitalization, resulting in high hospitalization costs and seriously threatening individuals' quality of life. A cost statistics shows that the mean total costs of childhood ALL were between $\$ 115,858$ and $\$ 163,350$ per patient. The important drivers of overall costs were hospital admissions (57\%) and medication (11-17\%) 
(van Litsenburg, Uyl-de Groot, Raat, Kaspers, \& Gemke, 2011). The financial burden of high costs is one of the most significant factors affecting patient compliance and has a direct impact on patients' willingness to be treated. Therefore, paying attention to the possible strategies on how to control hospitalization cost is considered beneficial. A number of international studies have estimated the hospitalization costs of patients with leukemia (DiNofia et al., 2018; Kaul et al., 2016; Tong et al., 2013). The results show that the number of days of hospitalization directly affects their hospitalization costs and treatment outcomes, with a positive correlation between the two. A retrospective analysis of the direct economic losses of 362

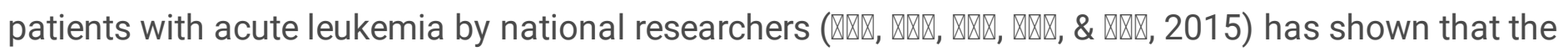
average total hospitalization cost was 34394 yuan for patients in the infected group and 14049 yuan for patients in the non-infected group, and the average hospitalization days was longer in the infected group $(P<0.05)$. It was concluded that the occurrence of hospital infection increased the economic burden of patients. In this study, we investigated the number of hospital days, hospital costs, type of infection, and antibiotic use in 205 patients with $\mathrm{Ph}+\mathrm{ALL}$ at our hospital. It was observed that in the low-intensity chemotherapy group, due to the reduced intensity of chemotherapy, the degree of suppression of the bone marrow by chemotherapy drugs is reduced and that the duration of bone marrow suppression after chemotherapy is shortened, thus reducing the severity of hospital infections in patients, as evidenced by the reduction of serious infections and the use of fewer types and lower intensity of antibiotics, thus shortening the number of hospital days and controlling the cost of antibiotic drugs and total costs. Currently, there is a paucity of the literature on the comprehensive cost analysis of acute leukemia treatment. Most of the available literature examine the cost-effectiveness of treatment methods; however, few of it analyze the impact of financial burden on patient survival.

Patients with $\mathrm{Ph}+\mathrm{ALL}$ are mostly older, have high WBC count, are at risk of central nervous system involvement, and are more likely to relapse with chemotherapy alone (Faiz, lqbal, \& Qureshi, 2015). Therefore, allo-HSCT is recommended for patients with $\mathrm{Ph}+\mathrm{ALL}$ who have achieved $\mathrm{CR}$ when possible. Although the advent of TKIs has changed the management of patients with $\mathrm{Ph}+\mathrm{ALL}$, chemotherapy combined with TKIs has been widely used to treat patients with $\mathrm{Ph}+\mathrm{ALL}$, improving the $\mathrm{CR}$ and long-term survival time and reducing the risk of relapse (Malagola, Papayannidis, \& Baccarani, 2016), bringing into question the status of allo-HSCT in the treatment of Ph + ALL. However, several national and international studies still demonstrate the survival benefit of allo-HSCT compared to combination chemotherapy in both the pre- and post-TKIs eras. The clinical significance of allo-HSCT was confirmed by the international randomized study GRAAPH-2005, which showed that among patients treated with imatinib in combination with chemotherapy (median age, 47 years), allogeneic transplantation in first remission prolongs RFS and OS (Y. Chalandon et al., 2015). Moreover, RFS and OS were shown to benefit allogeneic transplantation patients compared to those receiving vincristine and prednisone combined with dasatinib in a multicenter study in the USA (F. et al., 2016). In an analysis of 145 patients (median age, 37; range, 14-65 years) with $\mathrm{Ph}+\mathrm{ALL}$ at the Peking University People's Hospital treated with imatinib in combination with chemotherapy during the induction phase, $57.9 \%$ (77) of patients underwent allo-HSCT after remission, and the 4-year cumulative relapse, DFS, and OS rates in the transplant groups were $29.4 \%, 60.9 \%$, and $69.2 \%$, respectively, a significant advantage over the non-transplant group, especially in 
those with persistent MRD level (Wang et al., 2018). Our study compared the survival of transplanted and non-transplanted patients during treatment and showed that OS and DFS were significantly better in the transplant group than those in the non-transplant group, further suggesting that allo-HSCT can significantly improve long-term survival and prognosis in adults with $\mathrm{Ph}+\mathrm{ALL}$.

This study had a few limitations. According to MD Anderson et al. (Y Chalandon et al., 2015; Ravandi et al., 2013; Ravandi et al., 2015), more potent TKIs, for example, nilotinib and ponatinib, used as frontline therapy in combination with chemotherapy to reduce minimal residual disease significantly prolong patient survival. However, considering the small sample size in our study, the roles of second-and thirdgeneration TKIs in combination chemotherapy were not analyzed in this study. Moreover, in this study, the median age of patients in the transplant group was younger than that in the non-transplant group, and the non-transplant group included more patients with advanced disease, such as those with poor systemic status or refractory relapses, who were often lost to transplantation, which may have masked the efficacy of some TKIs combined with chemotherapy regimens.

In summary, WBC count, age, and CR in induction chemotherapy are independent prognostic factors affecting OS and DFS in patients with Ph + ALL. Furthermore, this study suggests that TKIs combined with reduced-dose chemotherapy is a practical option for patients with $\mathrm{Ph}+\mathrm{ALL}$ because it reduces chemotherapy-related adverse effects, lowers hospital costs, reduces patients' financial burden, and improves patient compliance without reducing CR rate and long-term survival. Moreover, the study showed that SCT in CR1 remains a good option for patients with Ph + ALL. These findings need to be further validated by multicenter, prospective clinical studies with larger sample sizes. Additionally, the treatment of $\mathrm{Ph}+\mathrm{ALL}$ continues to face serious problems of disease relapse and drug resistance, and further studies of novel biologic agents and antileukemic regimens such as immunotherapy will improve the outcome and prognosis of patients with $\mathrm{Ph}+\mathrm{ALL}$.

\section{Declarations}

Funding: This work was financially supported by construction project of Fujian medical center of hematology (Min201704). Sponsored by National and Fujian Provincial Key Clinical Specialty Discipline Construction Program, P. R.C.

Conflicts of interest/Competing interests: The authors declare that there are no conflicts of interest.

Availability of data and material: The datasets generated during and/or analyzed during the current study are available from the corresponding author on reasonable request. All data and materials support the published claims and comply with field standards. All the content has not been published elsewhere, nor is under consideration for publication anywhere else.

Code availability: Not applicable. 
Authors' contributions: All authors contributed to the study conception and design. Material preparation and data collection were performed by Chunping Wu and Mengting Zeng. Data analysis was performed by Chunping Wu. The first draft of the manuscript was written by Chunping Wu and all authors commented on previous versions of the manuscript. All authors read and approved the final manuscript.

Ethics approval: This was a retrospective study with no experimental interventions. This study was approved by the ethics review board of the Fujian Medical University Union Hospital.

Consent to participate: Informed consent was obtained from all the individual participants included in the study.

Consent for publication: Informed consent was obtained from all the individual participants included in the study.

\section{References}

1. Abou Dalle I, Jabbour E, Short NJ, Ravandi F (2019) Treatment of Philadelphia Chromosome-Positive Acute Lymphoblastic Leukemia. Curr Treat Options Oncol 20(1):4. doi:10.1007/s11864-019-0603-z

2. Bene MC, Bernier M, Casasnovas RO, Castoldi G, Knapp W, Lanza F,.. . van't Veer MB (1998) The reliability and specificity of c-kit for the diagnosis of acute myeloid leukemias and undifferentiated leukemias. The European Group for the Immunological Classification of Leukemias (EGIL). Blood 92(2):596-599

3. Bene MC, Castoldi G, Knapp W, Ludwig WD, Matutes E, Orfao A, van't Veer MB (1995) Proposals for the immunological classification of acute leukemias. European Group for the Immunological Characterization of Leukemias (EGIL). Leukemia 9(10):1783

4. Chalandon $Y$, Thomas X, Hayette S, Cayuela JM, Abbal C, Huguet F,.. . Lepretre S (2015) Randomized study of reduced-intensity chemotherapy combined with imatinib in adults with Ph-positive acute lymphoblastic leukemia. Blood 125(24):3711-3719

5. Chalandon $Y$, Thomas X, Hayette S, Cayuela JM, Abbal C, Huguet F,.. . Lepretre S (2015) Randomized study of reduced-intensity chemotherapy combined with imatinib in adults with Ph-positive acute lymphoblastic leukemia. Blood 125(24):3711-3719

6. Chiaretti S, Vitale A, Vignetti M, Piciocchi A, Fazi P, Elia L,.. . Foà R (2016) A sequential approach with imatinib, chemotherapy and transplant for adult $\mathrm{Ph}+$ acute lymphoblastic leukemia: final results of the GIMEMA LAL 0904 study. Haematologica 101(12):1544-1552. doi:10.3324/haematol.2016.144535

7. [Chinese guidelines for diagnosis and treatment of acute lymphoblastic leukemia(2016)] (2016) Zhonghua Xue Ye Xue Za Zhi 37(10):837-845. doi:10.3760/cma.j.issn.0253-2727.2016.10.002

8. DiNofia AM, Seif AE, Devidas M, Li Y, Hall M, Huang YV,... Aplenc R (2018) Cost comparison by treatment arm and center-level variations in cost and inpatient days on the phase III high-risk $B$ acute lymphoblastic leukemia trial AALL0232. Cancer Med 7(1):3-12. doi:10.1002/cam4.1206 
9. Ravandi F, Othus M, Forman SM (2016) US intergroup study of chemotherapy plus dasatinib and allogeneic stem cell transplant in Philadelphia chromosome positive ALL. Blood Advances 1(3):250259

10. Faiz M, Iqbal QJ, Qureshi A (2015) High prevalence of BCR-ABL fusion transcripts with poor prognostic impact among adult ALL patients: report from Pakistan. Asia Pac J Clin Oncol 7(1):4755

11. Fielding AK (2010) How I treat Philadelphia chromosome-positive acute lymphoblastic leukemia. Blood 116(18):3409-3417

12. Fielding AK, Rowe JM, Buck G, Foroni L, Gerrard G, Litzow MR,.. . Mcmillan AK (2014) UKALLXII/ECOG2993: addition of imatinib to a standard treatment regimen enhances long-term outcomes in Philadelphia positive acute lymphoblastic leukemia. Blood 123(6):843-850

13. Fielding AK, Rowe JM, Richards SM, Buck G, Moorman AV, Durrant IJ,.. . Lazarus HM (2009) Prospective outcome data on 267 unselected adult patients with Philadelphia chromosome-positive acute lymphoblastic leukemia confirms superiority of allogeneic transplantation over chemotherapy in the pre-imatinib era: results from the International ALL Trial MRC UKALLXII/ECOG2993. Blood 113(19):4489-4496

14. Fielding AK, Zakout GA (2013) Treatment of Philadelphia Chromosome-Positive Acute Lymphoblastic Leukemia. Current Hematologic Malignancy Reports 2011(2):231-237

15. Foà R, Vitale A, Vignetti M, Meloni G, Guarini A, De Propris MS,.. . Baccarani M (2011) Dasatinib as first-line treatment for adult patients with Philadelphia chromosome-positive acute lymphoblastic leukemia. Blood 118(25):6521-6528. doi:10.1182/blood-2011-05-351403

16. Haferlach T, Bacher U, Kern W, Schnittger S, Haferlach C (2007) Diagnostic pathways in acute leukemias: a proposal for a multimodal approach. Ann Hematol 86(5):311-327

17. Hatta Y, Mizuta S, Matsuo K, Ohtake S, Iwanaga M, Sugiura I,.. . Naoe T (2018) Final analysis of the JALSG Ph + ALL202 study: tyrosine kinase inhibitor-combined chemotherapy for Ph + ALL. Ann Hematol 97(9):1535-1545. doi:10.1007/s00277-018-3323-8

18. Kaul S, Korgenski EK, Ying J, Ng CF, Smits-Seemann RR, Nelson RE,.. . Kirchhoff AC (2016) A retrospective analysis of treatment-related hospitalization costs of pediatric, adolescent, and young adult acute lymphoblastic leukemia. Cancer Med 5(2):221-229. doi:10.1002/cam4.583

19. Leoni V, Biondi A (2015) Tyrosine kinase inhibitors in BCR-ABL positive acute lymphoblastic leukemia. Haematologica 100(3):295-299

20. Liu Q, Yang D, Feng S (2015) [The impact of imatinib on hematopoietic stem cell transplantation for Ph chromosome positive adult acute lymphoblastic leukemia]. Zhonghua Xue Ye Xue Za Zhi 36(9):805-808. doi:10.3760/cma.j.issn.0253-2727.2015.09.021

21. Malagola M, Papayannidis C, Baccarani M (2016) Tyrosine kinase inhibitors in Ph + acute lymphoblastic leukaemia: facts and perspectives. Ann Hematol 95(5):1-13

22. Martinelli G, Piciocchi A, Papayannidis C, Paolini S, Robustelli V, Soverini S,.. . Baccarani M (2017) First Report of the Gimema LAL1811 Phase II Prospective Study of the Combination of Steroids with 
Ponatinib As Frontline Therapy of Elderly or Unfit Patients with Philadelphia Chromosome-Positive Acute Lymphoblastic Leukemia. Blood 130(Supplement 1):99-99.

doi:10.1182/blood.V130.Suppl_1.99.99

23. Ottmann OG (2013) Management of Philadelphia chromosome-positive acute lymphoblastic leukemia. Current Hematologic Malignancy Reports 2011(2):231-237

24. Ravandi F, Jorgensen JL, Thomas DA, O'Brien S, Garris R, Faderl S,.. . Kantarjian HM (2013) Detection of MRD may predict the outcome of patients with Philadelphia chromosome-positive ALL treated with tyrosine kinase inhibitors plus chemotherapy. Blood 122(7):1214-1221. doi:10.1182/blood2012-11-466482

25. Ravandi F, O'Brien SM, Cortes JE, Thomas DM, Garris R, Faderl S,.. . Kantarjian HM (2015) Long-term follow-up of a phase 2 study of chemotherapy plus dasatinib for the initial treatment of patients with Philadelphia chromosome-positive acute lymphoblastic leukemia. Cancer 121(23):4158-4164. doi:10.1002/cncr.29646

26. Rousselot P, Coudé MM, Gokbuget N, Passerini G, Hayette C, Cayuela S, Ottmann JM, O. G (2016) Dasatinib and low-intensity chemotherapy in elderly patients with Philadelphia chromosome-positive ALL. Blood 128(6):774-782. doi:10.1182/blood-2016-02-700153

27. Salami K, Alkayed K, Halalsheh H, Hussein AA, Riziq M, Madanat F (2013) Hematopoietic stem cell transplant versus chemotherapy plus tyrosine kinase inhibitor in the treatment of pediatric Philadelphia chromosome-positive acute lymphoblastic leukemia (ALL). Hematology/ Oncology Stem Cell Therapy 6(1):34-41

28. Shen YJ, Zhu HH (2020) [Current treatment of adult Philadelphia chromosome-positive acute lymphoblastic leukemia in the TKI era]. Zhonghua Xue Ye Xue Za Zhi 41(9):779-782. doi:10.3760/cma.j.issn.0253-2727.2020.09.017

29. Tong WH, Van dS, Alleman IM, Van Litsenburg CJM, Kaspers RRL, Pieters GJL, R., \& Uyl-De Groot CA (2013) Cost-analysis of treatment of childhood acute lymphoblastic leukemia with asparaginase preparations: the impact of expensive chemotherapy. Haematologica, 98(5)

30. van Litsenburg RR, Uyl-de Groot CA, Raat H, Kaspers GJ, Gemke RJ (2011) Cost-effectiveness of treatment of childhood acute lymphoblastic leukemia with chemotherapy only: the influence of new medication and diagnostic technology. Pediatr Blood Cancer 57(6):1005-1010. doi:10.1002/pbc.23197

31. Wang J, Jiang Q, Xu LP, Zhang XH, Chen H, Qin YZ,.. . Huang XJ (2018) Allogeneic Stem Cell Transplantation versus Tyrosine Kinase Inhibitors Combined with Chemotherapy in Patients with Philadelphia Chromosome-Positive Acute Lymphoblastic Leukemia. Biol Blood Marrow Transplant 24(4):741-750. doi:10.1016/j.bbmt.2017.12.777

32. Wang SH, Wang JN, Liu YH, Wu XH, Li YX (2015) Study on the direct economic losses of nosocomial infections in acute leukemia patients. Chinese Journal of Hospital Infection 000(015):3578-3579. doi:10.11816/cn.ni.2015-141853 (in Chinese) 


\section{Tables}

Table 1. Patient characteristics 


\begin{tabular}{|c|c|c|c|c|c|c|}
\hline Group & $\begin{array}{l}\text { Standard } \\
\text { chemotherapy } \\
\text { group }\end{array}$ & $\begin{array}{l}\text { Reduced-dose } \\
\text { chemotherapy } \\
\text { group }\end{array}$ & $\mathrm{P}$ & $\begin{array}{l}\text { Transplant } \\
\text { group }\end{array}$ & $\begin{array}{l}\text { Non- } \\
\text { transplant } \\
\text { group }\end{array}$ & $\mathrm{P}$ \\
\hline & $N=143$ & $N=62$ & & $N=55$ & $N=143$ & \\
\hline Gender [cases (\%)] & & & 0.176 & & & 0.307 \\
\hline Male & $77 \rrbracket 53.8 \rrbracket$ & $27 \rrbracket 43.5 \rrbracket$ & & $31 \rrbracket 56.4 \rrbracket$ & $69 \rrbracket 48.3 \rrbracket$ & \\
\hline Female & $66 \rrbracket 46.2 \rrbracket$ & $35 \rrbracket 56.5 \rrbracket$ & & $24 \llbracket 43.6 \rrbracket$ & $74 \rrbracket 51.7 \rrbracket$ & \\
\hline $\begin{array}{l}\text { Age(years) \mean } \\
\text { (range) }\end{array}$ & $39(14-73)$ & 41凶14-73囚 & 0.467 & 31ه14-59® & $42 \otimes 14-73 \rrbracket$ & $<0.001$ \\
\hline $\begin{array}{l}\text { WBC count } \\
\square \times 10^{\wedge} 9 / L \mathbb{}\end{array}$ & $\begin{array}{l}89.93 \rrbracket 1.5- \\
504.64 \rrbracket\end{array}$ & $\begin{array}{l}78.17 \rrbracket 1.1- \\
974.82 \rrbracket\end{array}$ & 0.515 & $\begin{array}{l}77.86 \\
\bigotimes 1.10- \\
470.84 \rrbracket\end{array}$ & $\begin{array}{l}89.48 \\
\bigotimes 1.50- \\
974.82 \rrbracket\end{array}$ & 0.552 \\
\hline $\mathrm{HB}(\mathrm{g} / \mathrm{L})$ & $91 \rrbracket 32-160 \rrbracket$ & $90 \rrbracket 43-161 \rrbracket$ & 0.921 & $\begin{array}{l}87 \rrbracket 32- \\
160 \rrbracket\end{array}$ & $\begin{array}{l}91 \rrbracket 38- \\
161 \rrbracket\end{array}$ & 0.335 \\
\hline $\begin{array}{l}\text { PLT count } \\
\triangle \times 10^{\wedge} 9 / \mathrm{L} \rrbracket\end{array}$ & $59 ه 1-356 \rrbracket$ & $52 \bowtie 3-329 \rrbracket$ & 0.525 & $58 \rrbracket 4-248 \rrbracket$ & $57 \rrbracket 1-356 \rrbracket$ & 0.937 \\
\hline $\begin{array}{l}\text { Immunophenotype } \\
\text { [cases (\%)] }\end{array}$ & & & 0.315 & & & 0.019 \\
\hline B lymphatic & 106ख74.1区 & $50 \rrbracket 80.6 \rrbracket$ & & $35 \rrbracket 63.6 \rrbracket$ & $114 \llbracket 79.7 \rrbracket$ & \\
\hline $\begin{array}{l}\text { B lymphatic with } \\
\text { myeloid } \\
\text { expression }\end{array}$ & $37 \rrbracket 25.9 \rrbracket$ & $12 \rrbracket 19.4 \rrbracket$ & & $20 \rrbracket 36.4 \rrbracket$ & $29 \rrbracket 20.3 \rrbracket$ & \\
\hline $\begin{array}{l}\text { Chromosome type } \\
\text { [cases (\%)] }\end{array}$ & & & 0.208 & & & 0.888 \\
\hline $\mathrm{Ph}+$ only & $40 \rrbracket 28.0 \rrbracket$ & $12 \bigotimes 19.4 \rrbracket$ & & $12 \rrbracket 21.8 \rrbracket$ & $39 \rrbracket 27.3 \rrbracket$ & \\
\hline $\begin{array}{l}\text { Ph+ plus } \\
\text { additional } \\
\text { changes }\end{array}$ & $30 \rrbracket 21.0 \rrbracket$ & $21 \otimes 33.9 \rrbracket$ & & $14 \bowtie 25.5 \rrbracket$ & $35 \rrbracket 24.5 \rrbracket$ & \\
\hline Normal karyotype & $44 \llbracket 30.8 \rrbracket$ & 19ه30.6ه & & $18 \rrbracket 32.7 \rrbracket$ & $43 \rrbracket 30.1 \rrbracket$ & \\
\hline Unknown & $29 \llbracket 20.2 \rrbracket$ & $10 \otimes 16.1 \rrbracket$ & & $11 \rrbracket 20.0 \otimes$ & $26 \rrbracket 18.2 \rrbracket$ & \\
\hline $\begin{array}{l}\text { BCR-ABL type } \\
\text { [cases (\%)] }\end{array}$ & & & 0.244 & & & 0.675 \\
\hline P190 & $59 \llbracket 41.3 \rrbracket$ & $24 \llbracket 38.7 \rrbracket$ & & $21 \llbracket 38.2 \rrbracket$ & $58 \rrbracket 40.6 \rrbracket$ & \\
\hline P210 & $31 \rrbracket 21.7 \rrbracket$ & $20 \rrbracket 32.3 \rrbracket$ & & $16 \rrbracket 29.1 \rrbracket$ & $33 \rrbracket 23.1 \rrbracket$ & \\
\hline Unknown & $53 \otimes 37.0 \otimes$ & $18 \otimes 29.0 \rrbracket$ & & 18邓32.7区 & $52 \rrbracket 36.4 \rrbracket$ & \\
\hline
\end{tabular}


Table 2. Adverse events in induction chemotherapy

\begin{tabular}{|c|c|c|c|}
\hline \multirow[t]{2}{*}{ Group } & $\begin{array}{l}\text { Standard chemotherapy } \\
\text { group }\end{array}$ & $\begin{array}{l}\text { Reduced-dose chemotherapy } \\
\text { group }\end{array}$ & $P$ \\
\hline & $N=143$ & $N=62$ & \\
\hline \multicolumn{4}{|l|}{$\begin{array}{l}\text { Complications } \\
\text { [cases (\%)] }\end{array}$} \\
\hline Pulmonary infection & $99 \llbracket 69.2 \rrbracket$ & $34 \rrbracket 54.8 \rrbracket$ & 0.047 \\
\hline Bloodstream infection & $42 \rrbracket 29.4 \rrbracket$ & $9 \otimes 14.5 \rrbracket$ & 0.024 \\
\hline $\begin{array}{l}\text { Intestinal and perianal } \\
\text { infection }\end{array}$ & $21(14.7)$ & $12 \rrbracket 19.4 \rrbracket$ & 0.403 \\
\hline Oral infection & $49 \llbracket 34.3 \rrbracket$ & $15 \rrbracket 24.2 \rrbracket$ & 0.276 \\
\hline Other infections & $34 \rrbracket 23.8 \rrbracket$ & $16 \rrbracket 25.8 \rrbracket$ & 0.756 \\
\hline Superficial bleeding & $40 \rrbracket 28.0 \rrbracket$ & $11 \otimes 17.7 \rrbracket$ & 0.120 \\
\hline Visceral bleeding & $18 \rrbracket 12.6 \rrbracket$ & $4 \llbracket 6.5 \rrbracket$ & 0.192 \\
\hline Liver function impairment & $33 \rrbracket 23.1 \rrbracket$ & $9814.5 \rrbracket$ & 0.163 \\
\hline
\end{tabular}

Table 3. Number of hospital days and hospitalization costs of patients with Philadelphia ( $\mathrm{Ph}+)$ chromosome-positive acute lymphoblastic leukemia

\begin{tabular}{|lllr|}
\hline Group & $\begin{array}{l}\text { Standard chemotherapy } \\
\text { group }\end{array}$ & $\begin{array}{l}\text { Reduced-dose chemotherapy } \\
\text { group }\end{array}$ & $\mathrm{P}$ \\
\cline { 2 - 4 } & $\mathrm{N}=143$ & $\mathrm{~N}=62$ & \\
\hline hospital days(mean) & $27 \pm 8$ & $23 \pm 7$ & $<0.001$ \\
\hline $\begin{array}{l}>21 \text { days of } \\
\text { hospitalization }\end{array}$ & $80.4 \%(115 / 143)$ & $52.4 \%(33 / 62)$ & $<0.001$ \\
\hline Total cost $(¥)$ & $73309 \pm 3610$ & $51185 \pm 3586$ & 0.026 \\
\hline Antimicrobial cost $(¥)$ & $23215 \pm 2053$ & $15019 \pm 1872$ & 0.019 \\
\hline Blood products cost $(¥)$ & $7193 \pm 443$ & $5901 \pm 705$ & 0.122 \\
\hline Examination cost $(¥)$ & $12971 \pm 1254$ & $9969 \pm 501$ & 0.143 \\
\hline
\end{tabular}




\section{Table 4. Antibiotic use in induction chemotherapy}

\begin{tabular}{|c|c|c|c|}
\hline \multirow[t]{2}{*}{$\begin{array}{l}\text { Group } \\
\text { [cases (\%)] }\end{array}$} & $\begin{array}{l}\text { Standard } \\
\text { chemotherapy } \\
\text { group }\end{array}$ & $\begin{array}{l}\text { Reduced-dose } \\
\text { chemotherapy group }\end{array}$ & $\mathrm{P}$ \\
\hline & $N=143$ & $N=62$ & \\
\hline Use $>4$ antibiotics & $64 \rrbracket 44.8 \rrbracket$ & $14 \rrbracket 22.6 \rrbracket$ & 0.003 \\
\hline Carbapenems & 107ه74.8\ & $38 \bowtie 61.3 \rrbracket$ & 0.057 \\
\hline $\begin{array}{l}\text { Restricted anti-positive drugs (tigecycline, } \\
\text { vancomycin, linezolid) }\end{array}$ & $42 \varangle 29.4 \rrbracket$ & $9 \otimes 14.5 \rrbracket$ & 0.024 \\
\hline Restricted tigecycline and/or polymyxin & 15(10.5) & $1 \otimes 1.6 \otimes$ & 0.031 \\
\hline Antifungal & $90 \rrbracket 62.9 \rrbracket$ & $34 \rrbracket 54.8 \rrbracket$ & 0.309 \\
\hline
\end{tabular}

Table 5. Multivariate analysis of overall survival and disease-free survival

\begin{tabular}{|lllllll|}
\hline & \multicolumn{2}{c}{ OS } & \multicolumn{4}{c|}{ DFS } \\
\hline Variables & HR & $95 \% \mathrm{Cl}$ & $\mathrm{P}$ & $\mathrm{HR}$ & $95 \% \mathrm{Cl}$ & $\mathrm{P}$ \\
\hline Age & 1.027 & $1.012-1.043$ & $<0.001$ & 1.027 & $1.010-1.043$ & 0.001 \\
\hline WBC count & 1.003 & $1.001-1.005$ & 0.003 & 1.004 & $1.002-1.006$ & 0.001 \\
\hline CR in induction & 2.223 & $1.387-3.563$ & 0.001 & 2.245 & $1.310-3.846$ & 0.003 \\
\hline
\end{tabular}

\section{Figures}


A

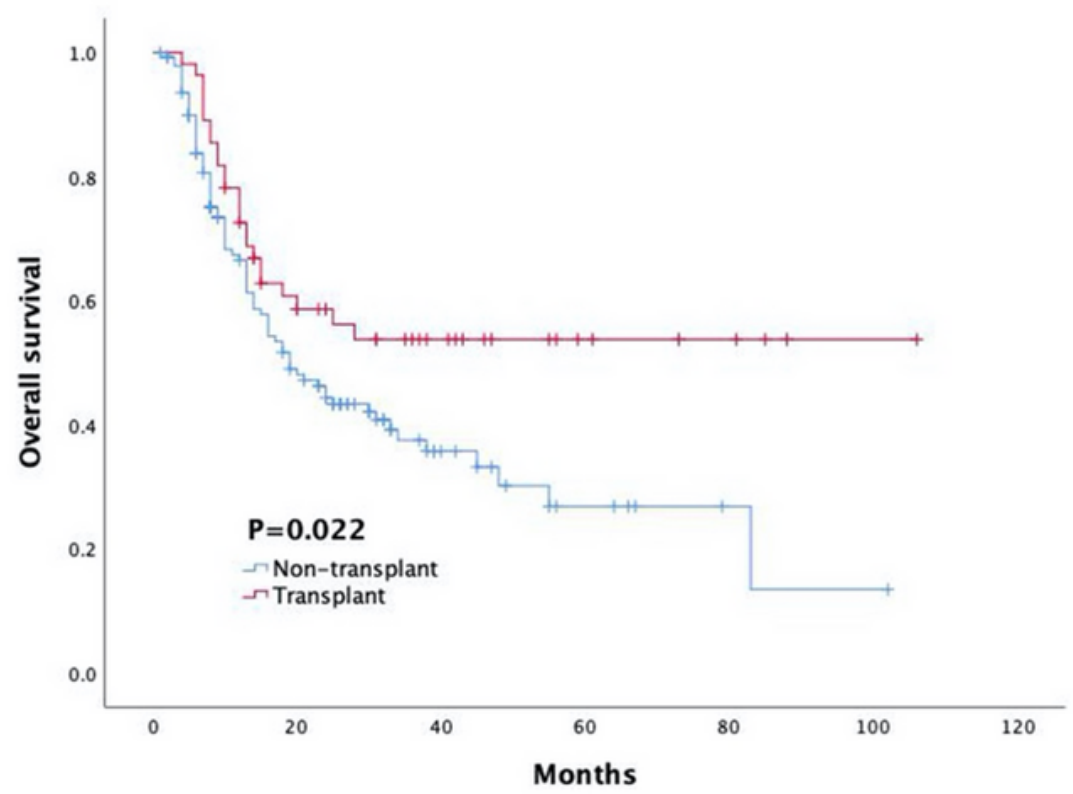

B

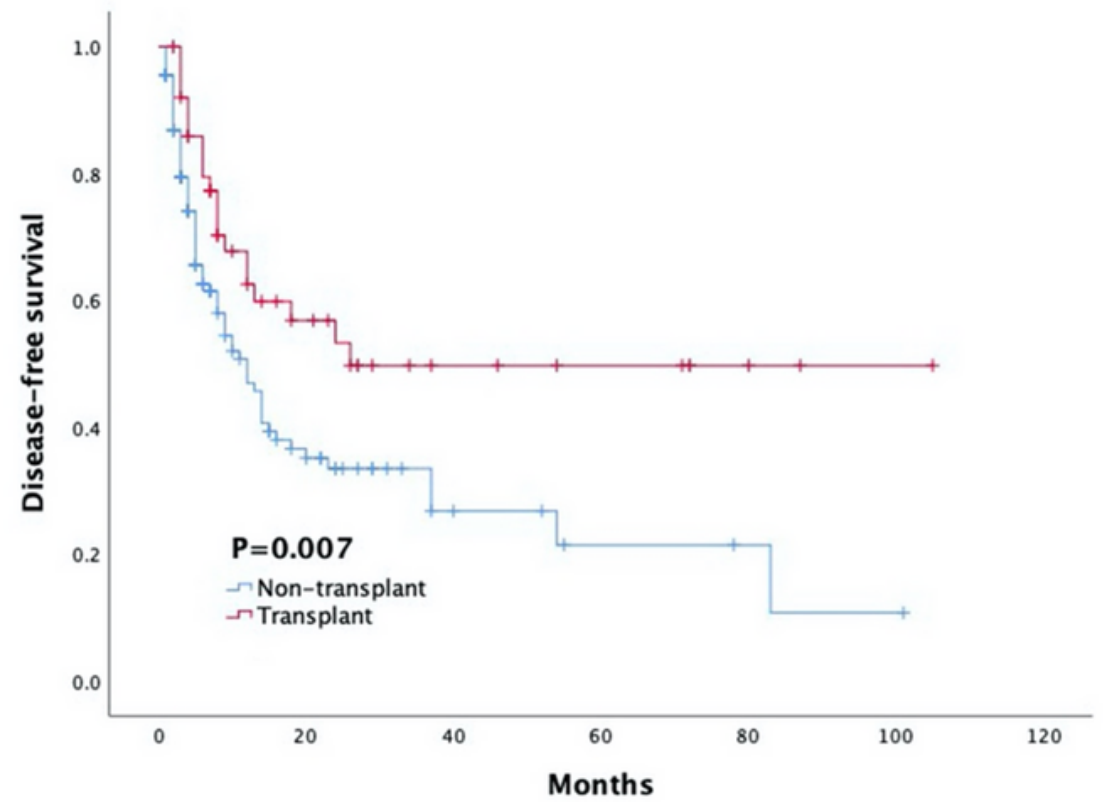

Figure 1

Survival outcomes (A) Overall survival; (B) Disease-free survival 